\title{
Embryo vascularization by three-dimensional power Doppler ultrasonography at 7-10 weeks of pregnancy
}

\author{
João Bortoletti Filho, Luciano Marcondes \\ Machado Nardozza, Edward Araujo Júnior*, \\ Liliam Cristine Rolo, Paulo Martin Nowak, \\ Hélio Antonio Guimarães Filho and Antonio \\ Fernandes Moron
}

Department of Obstetrics, São Paulo Federal University (UNIFESP), São Paulo, SP, Brazil

\begin{abstract}
Aim: Assess vascular indices of 7-10 week embryos using three-dimensional power Doppler (3DPD) and correlate them with the crown-rump length (CRL).

Methods: This cross-sectional study included 65 healthy pregnancies between 7 and 10 weeks. The three-dimensional volume of the embryo was obtained using an endocavitary volumetric transducer and the VOCAL (Virtual Organ Computer-aided Analysis) method, with a $12^{\circ}$ rotation angle and 15 sequential planes. The vascularization (VI), flow (FI) and the vascular and flow (VFI) indices were obtained using 3DPD and the mean, median, standard deviation, maximum and minimum values were calculated for each gestational age. Pearson's correlation coefficient ( $r$ ) was used to evaluate the correlation between vascular indices and CRL.

Results: The VI ranged from 0.77 to 41.67 , mean 14.68 ( \pm 8.60 ), the $\mathrm{FI}$ went from 25.71 to 139.50 , mean 90.61 $( \pm 21.51)$ and the VFI from 0.20 to 81.57 , mean 15.69 ( \pm 12.42$)$. The correlation between $C R L$ and all 3D power Doppler vascular indices was low (VI $-r=-0.073$, $\mathrm{P}=0.566 ; \mathrm{FI}-\mathrm{r}=0.173, \mathrm{P}=0.168$ and $\mathrm{VFI}-\mathrm{r}=-0.004$, $\mathrm{P}=0.974$ ).

Conclusion: 3D power Doppler vascular indices in 7-10 week embryos do not correlate with CRL.
\end{abstract}

Keywords: Crown-rump length; embryo; power Doppler; three-dimensional imaging.

\footnotetext{
${ }^{*}$ Corresponding author:

Edward Araujo Júnior, PhD

Rua Carlos Weber

950 apto 113 Visage

Alto da Lapa

São Paulo, SP

Brazil, CEP 05303-000

Tel./Fax: +55-11-3294-3220

E-mail: araujojred@terra.com.br
}

\section{Introduction}

Ultrasound is useful to assess embryological development and thus monitor pregnancy and detect early signs of obstetric pathologies [14]. It is now possible to obtain detailed information on embryonic development using transvaginal probes [11]

It has been demonstrated that two-dimensional ultrasound (2DUS) is less accurate than three-dimensional ultrasound (3DUS) in the volumetric evaluation of irregularly shaped objects [26]. This is especially relevant for $1^{\text {st }}$ trimester pregnancies due to the irregular shape of both the gestational sac and embryo. Blass et al. [5] developed a method that used multiple bi-dimensional planes for the three-dimensional reconstruction of the human embryo. Aviram et al. [2] recently published a reference curve for the volume of 6-12 week embryos using the VOCAL (Virtual Organ Computer-aided Analysis) method. This method offers the possibility of modifying contours in one plane, thus improving final volume accuracy [24].

Through the recent introduction of three-dimensional power Doppler (3DPD) to obstetric sonography, it is now possible to quantitatively assess blood flow to the placenta [22, 30] and fetal organs [6, 7]. Three-dimensional power Doppler is better than conventional color Doppler in the evaluation of low-velocity blood flows, such as occurs in the intervillous space during the $1^{\text {st }}$ trimester of pregnancy [29]. Through 3DPD it is possible to study the vascular architecture of the embryo and to quantify blood flows using the vascular index (VI) and the vascular flow index (VFI) [16].

The aim of this study was to evaluate vascular indices of healthy pregnancies using 3DPD and correlate these with the crown-rump length (CRL) of embryos between $7-10$ weeks of gestational age.

\section{Methods}

A prospective cross-sectional study involving 65 healthy pregnant women (at 7-10 weeks' gestation) was performed between November 2005 and March 2007. The study was approved by the Ethics Committee (protocol number 1492/06) of São Paulo Federal University (UNIFESP) and all participants gave written informed consent.

All participants were low-risk patients managed at UNIFESP prenatal clinic. The inclusion criteria were: (1) singleton pregnancy with a live embryo; (2) gestational age < 10 weeks; and (3) no history of vaginal bleeding in the index pregnancy. Ges- 
tational age was calculated according to the first day of the last menstrual period and confirmed by sonographic crown-rump measurement performed before the $10^{\text {th }}$ week. The exclusion criteria were: (1) women with any chronic diseases (diabetes, hypertension, auto-immune conditions) and (2) smokers or drug users in the index pregnancy.

Examinations were performed at the 3DUS unit of the Obstetrics Department of UNIFESP, by two operators (JBF and LCR), both with three years of experience in obstetric 3DUS. One of two pieces of equipment was used for scanning: a SONOACE 8000Live or an Accuvix XQ (Medison, Seoul, Korea), both equipped with multifrequential endocavitary volumetric transducers. All off-line analyses of 3DPD vascular indices were done by a single operator (JBF). Each patient was examined only once.

First a 2-dimensional real-time ultrasound was performed to assess CRL, mean gestational sac diameter (arithmetic mean of 3 the largest diameters) and embryonic heart rate. The Virtual Organ Computer-aided Analysis (VOCAL) method was used to obtain embryonic volumes. After switching to the 3D mode, the region of interest $(\mathrm{ROI})$ box was positioned over the embryo and the scanning angle was set at $30^{\circ}$, with a normal scanning speed (automatic volume acquisition in 4 seconds). After scanning, the embryo was automatically displayed on the monitor as three simultaneous orthogonal perpendicular planes (axial, sagittal and coronal). The sagittal plane was magnified $50 \%$ and arbitrarily chosen as the reference plane. The image of the embryo was moved to the center of the plane and rotated around the $Y$ axis, so that the largest axis of the embryo was displayed horizontally. Then the VOCAL switch was activated using a $12^{\circ}$ rotation angle and the manual trace setting. Calipers were positioned on the superior and inferior extremities of the embryo and after obtaining 15 sequential planes, the equipment automatically displayed the reconstructed image and its volume in $\mathrm{cm}^{3}$.

The following settings were used for the 3D power Doppler: average frame (10), penetration frequency (low); enhance (1), reject (8), gain (50), frame average (2), sensitivity (15), density (on), balance (16), scale (1.5 kHz) and filter (1). After activating the VOCAL shell histogram switch, the equipment automatically displayed the 3DPD indices (VI, FI and VF1) (Figure 1).

The $\mathrm{VI}$ is expressed as a percentage and identifies the number of colored voxels in the ROI, which is an estimate of the number of vessels within that tissue. The flow index (FI) is the average color value of all the color voxels, and it shows the average blood flow intensity. The vascularization flow index (VFI) is the average color value of all the gray and color voxels of the sphere and represents both blood flow and vascularization.

In this study, the thermal index throughout the examination period ranged from 0.6 to 0.7 and the maximum mechanical index was 0.3 . These values are within the safety limits for Doppler established by the European Committee for Radiation Safety [9] and by the American Institute of Ultrasound in Medicine [1].

All pregnancies were followed up to the $22^{\text {nd }}$ week. Cases with fetal structural malformations detected during the anatomy scan as well as those that resulted in gestational losses were excluded.

All data were collected on an Excel spreadsheet (Microsoft, USA) and the software SPSS 13.0 for Windows (SPSS Inc, Chicago, IL, USA) was used for statistical calculations. Maternal age, gestational age and parity are presented as means, medians, standard-deviation (SD), minimum and maximum values. Power Doppler vascular indices are presented as means, SD,

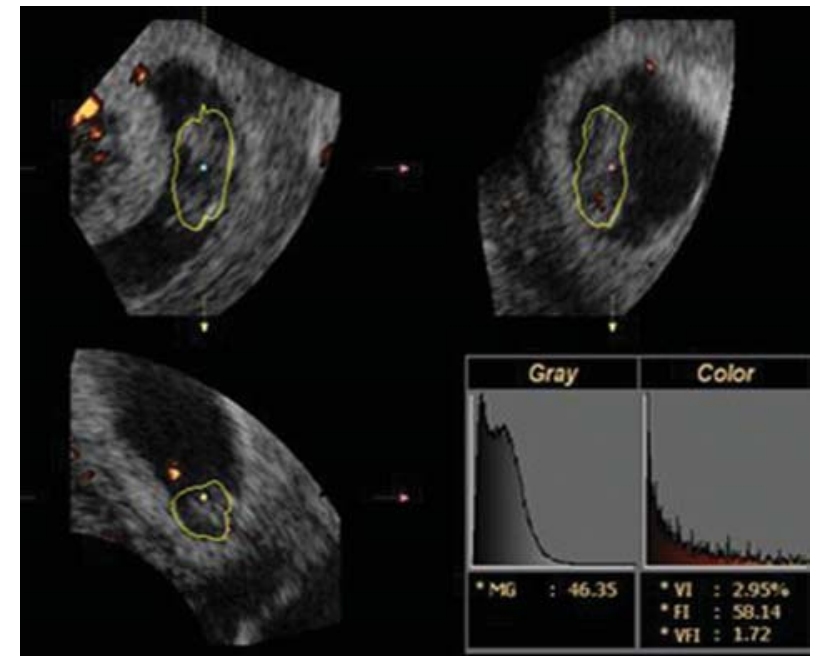

Figure 1 Automatic representation of 3D power Doppler vascular indices ( $\mathrm{VI}, \mathrm{FI}$ and $\mathrm{VFI}$ ) after three-dimensional volume reconstruction of the embryo using the VOCAL method with a $12^{\circ}$ rotation angle. $\mathrm{VI}=$ vascularization index; $\mathrm{FI}=$ flow index; $\mathrm{VFI}=$ vascular and flow index; VOCAL = Virtual Organ Computeraided Analysis.

minimum and maximum for each gestational age. Pearson's correlation coefficient ( $r$ ) was used to assess the correlation between vascular indices and CRL. Significance was established at $\mathrm{P}<0.05$.

\section{Results}

A total of 74 women were initially enrolled. Two were excluded because thermal indices were over 1.0 and 7 were excluded because of poor quality of the volumes obtained, due to transmission artifacts, which precluded the evaluation of vascular indices. The 65 remaining participants constituted the study population and all reached the $22^{\text {nd }}$ week of pregnancy with live fetuses.

Maternal age ranged from 20 to 41 years $(30.1 \pm 5.8)$, the number of previous pregnancies was 1 to 9 $(2.3 \pm 1.7)$, gestational age ranged from 7 to 10 weeks $(8.7 \pm 1.0)$ and $\mathrm{CRL}$ ranged from 9.0 to $39.7 \mathrm{~mm}$ $(23.94 \pm 7.95)$. The $\mathrm{VI}$ ranged from 0.77 to 41.64 (14.68 \pm 8.60$)$, the $\mathrm{FI}$ ranged from 25.71 to 139.50 $(90.61 \pm 21.51)$ and the $\mathrm{VFI}$ ranged from 0.20 to 81.57 $(15.69 \pm 12.42)$. Table 1 presents the mean, SD, median, maximum and minimum values for the vascularization indices according to gestational age.

Pearson's correlation coefficient $(r)$ for $C R L$ and vascular indices (VI, FI and VFI) ranged from -1 to 1 . The $\mathrm{P}$-value for the correlation coefficient indicated a null hypothesis, that is $r=0$. The non-significant $P$-values $(>0.05)$ indicated a lack of correlation between these two parameters. As depicted on Figures 2, 3 and 4, there was a low correlation between power Doppler vascular 
Table $13 D$ power Doppler vascularization indices between 7 and 10 weeks of pregnancy.

\begin{tabular}{|c|c|c|c|c|c|c|c|}
\hline $\begin{array}{l}\text { 3D power Doppler } \\
\text { vascular indices }\end{array}$ & $\begin{array}{l}\text { GA } \\
\text { (weeks) }\end{array}$ & Mean & Median & SD & Maximum & Minimum & $\mathrm{n}$ \\
\hline \multirow[t]{4}{*}{$\mathrm{VI}$} & 7 & 17.09 & 16.45 & 5.23 & 8.21 & 27.63 & 10 \\
\hline & 8 & 12.96 & 14.13 & 11.00 & 0.77 & 41.64 & 17 \\
\hline & 9 & 15.26 & 14.12 & 8.25 & 2.11 & 41.02 & 22 \\
\hline & 10 & 14.19 & 12.77 & 8.19 & 4.12 & 35.51 & 16 \\
\hline \multirow[t]{4}{*}{$\mathrm{FI}$} & 7 & 83.78 & 86.21 & 23.34 & 38.92 & 114.14 & 10 \\
\hline & 8 & 85.24 & 87.13 & 27.02 & 25.71 & 139.50 & 17 \\
\hline & 9 & 96.45 & 102.22 & 17.64 & 47.90 & 119.97 & 22 \\
\hline & 10 & 92.55 & 96.10 & 17.75 & 59.13 & 124.27 & 16 \\
\hline \multirow[t]{4}{*}{ VFI } & 7 & 16.00 & 13.98 & 6.18 & 8.26 & 30.02 & 10 \\
\hline & 8 & 16.70 & 12.72 & 19.90 & 0.20 & 81.57 & 17 \\
\hline & 9 & 15.46 & 15.16 & 9.14 & 1.01 & 39.07 & 22 \\
\hline & 10 & 14.71 & 13.82 & 9.68 & 3.00 & 37.21 & 16 \\
\hline
\end{tabular}

$\mathrm{VI}=$ vascularization index; $\mathrm{FI}=$ flow index; $\mathrm{VFI}=$ vascularization flow index; $\mathrm{GA}=$ gestational age; $\mathrm{SD}=$ standard deviation; $\mathrm{n}=$ number of fetuses examined at each gestational age.

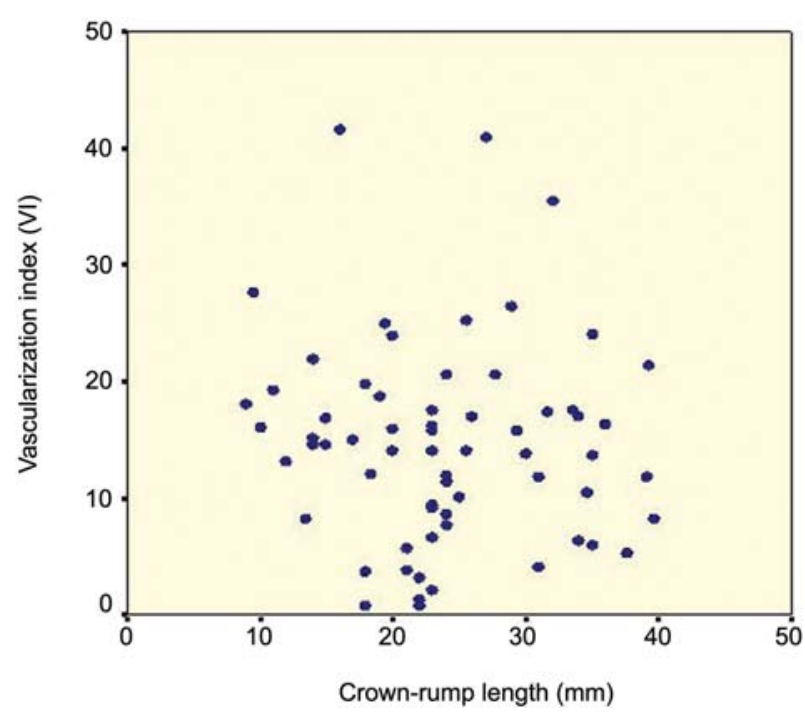

Figure 2 Correlation between vascularization index and crownrump length $(r=0.073 ; P=0.566)$.

indices and $\mathrm{CRL}(\mathrm{r}=0.073, \mathrm{P}=0.566$ for $\mathrm{VI} ; \mathrm{r}=0.173$, $\mathrm{P}=0.168$ for $\mathrm{FI}$ and $\mathrm{r}=-0.004, \mathrm{P}=0.974$ for $\mathrm{VFI}$ ).

\section{Discussion}

Various first trimester sonographic parameters such as yolk sac [8], embryonic heart rate [4] and gestational sac growth [23] have been linked with adverse pregnancy outcomes.

Since 3DUS allows tracing of the external surface, it is more accurate than 2DUS in evaluating the volume of irregularly shaped objects and it has been previously used to assess several $1^{\text {st }}$ trimester structures, such as the gestational sac [18], amniotic fluid [12] and yolk sac

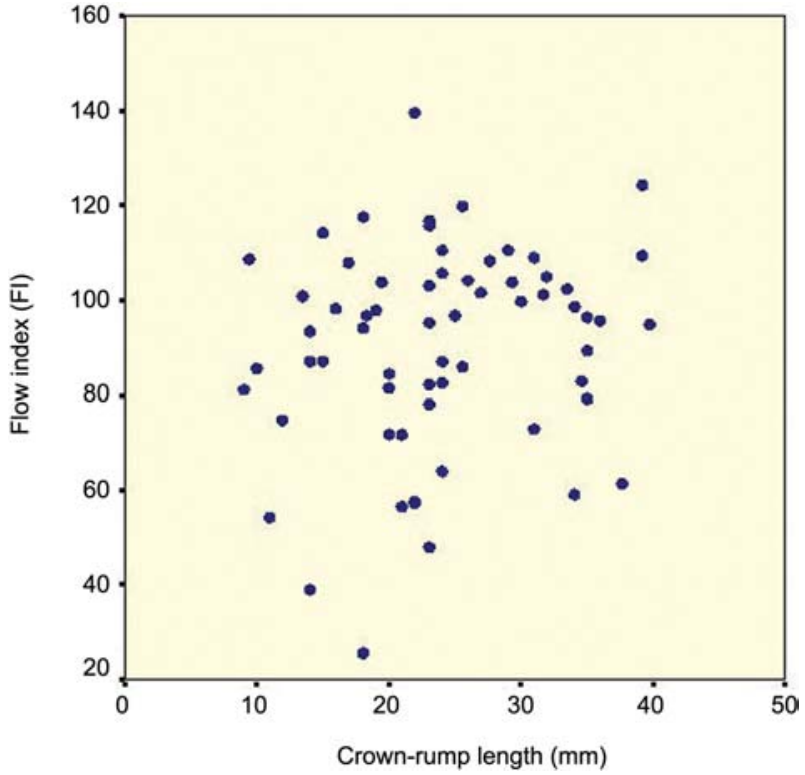

Figure 3 Correlation between flow index and crown-rump length $(r=0.173 ; P=0.168)$.

[28]. Blass et al. [5] developed a program (Vingmed EchoPAC-3D software) that enabled the three-dimensional reconstruction of embryos through US manual tracing of multiple parallel 2-dimensional planes. Aviram et al. [2] used the VOCAL method with a $30^{\circ}$ rotation to evaluate the volume of 72 embryos and fetuses between 6 and 12 weeks of gestation and reported a strong correlation between this volume and the CRL $(r=0.939)$. According to these authors, while the volume increased 35 times, CRL increased only 4.5 times. This suggests that volume may be a better parameter than a single longitudinal measure to evaluate embryonic growth during the $1^{\text {st }}$ trimester. 


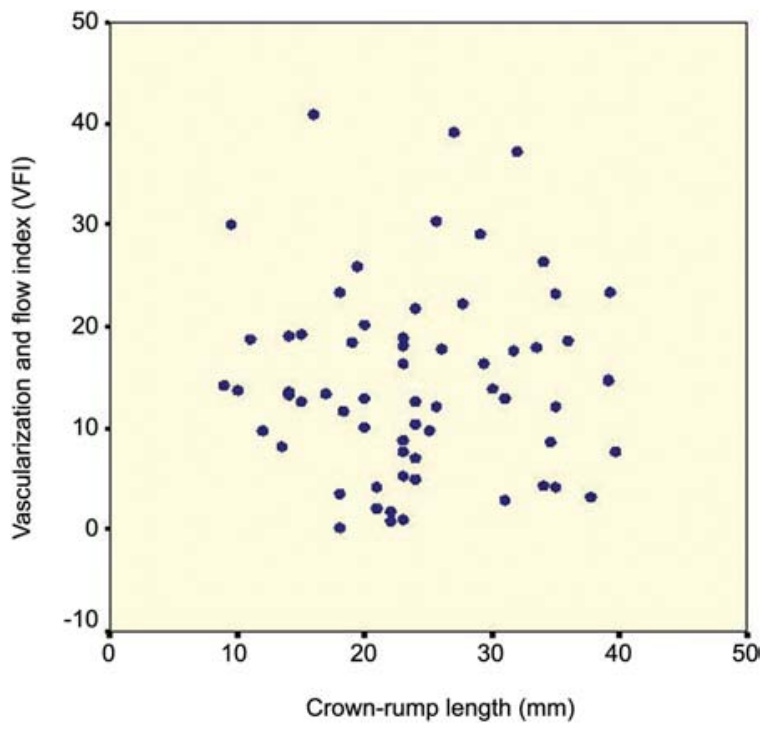

Figure 4 Correlation between vascularization and flow index and crown-rump length $(r=-0.004 ; P=0.974)$.

We used the VOCAL method to measure the volume of the embryo because this method is more accurate than the multiplanar method to assess the volume of irregular objects [25]. Moreover, the VOCAL method offers the possibility of modifying the contours in one plane, which increases the accuracy of the final volume [24]. The SonoView Pro software (Medison, Seoul, Korea) offers $30^{\circ}, 18^{\circ}$ and $12^{\circ}$ rotation angles. In this study we decided to use the $12^{\circ}$ rotation and trace 15 planes. Raine-Fenning et al. [25] measured the volume of differently shaped and sized objects and reported that measures obtained with a $6^{\circ}$ rotation angle were more reproducible than other techniques, except for the $9^{\circ}$ rotation, and significantly more accurate than the measures obtained with a $30^{\circ}$ rotation angle. Using an endometrium-like experimental model, Martins et al. [19] reported that measures obtained using the VOCAL method with a $15^{\circ}$ rotation angle (12 planes) were reproducible and accurate.

The color and brightness of the image exhibited in the power Doppler mode reflect the total energy of the Doppler signal. This type of Doppler is angle independent, detects low velocity flows and avoids the aliasing effect of conventional color Doppler studies. Power Doppler is able to detect low resistance blood flows in small structures, such as occurs in the intervillous space [17]. Yu et al. [30] evaluated vascularization of 100 placentas between 20 and 40 weeks using the VOCAL method with a $30^{\circ}$ angle and manual surface tracing and reported that all 3D power Doppler vascular indices were strongly correlated with gestational age $(r=0.84$ for $\mathrm{VI}, r=0.49$ for $\mathrm{FI}$ and $r=0.82$ for $V F I)$. Mercé et al. [22] proposed a new technique to assess placental vessels using 3D power
Doppler, which they named placental biopsy. This technique uses the VOCAL method to obtain a sphere of the placenta, as a representative sample of the whole placenta. According to these authors, all indices were correlated with gestational age. The Fl exhibited the highest correlation $(r=0.58 ; P<0.001)$ while the $\mathrm{VI}$ had the lowest correlation $(r=0.29 ; P=0.025)$.

The reproducibility of the 3D power Doppler indices depends on the technique used to obtain the volume of interest. Mercé et al. [21] measured the volumes of 30 placentas using a technique called "placental biopsy" and calculated the intraobserver variability. According to these authors, all vascular indices had a correlation above 0.85 and the flow indices had the highest intraobserver agreement. For the embryo, where volumes are obtained through the outline of the external surface, the VOCAL method has also been shown to have good intraand inter-observer reproducibility for the estimation of the fetal trunk and head volumes, obtained through the outline of external surfaces between $11+0$ to $13+6$ weeks [10].

There is only one previous publication evaluating $1^{\text {st }}$ trimester embryonic vascularization using 3DPD. In that study, Kurjak et al. [16] evaluated 25 embryos between 5-7 weeks of pregnancy using the VOCAL method with a $30^{\circ}$ rotation and reported no correlation between CRL and 3DPD vascular indices $\left(\mathrm{R}^{2}=0.02\right.$ for $\mathrm{VI}$ and $\mathrm{R}^{2}=0.01$ for $\mathrm{VFI})$. The $\mathrm{VI}$ and $\mathrm{VFI}$ remained practically unchanged during the whole study period. These authors concluded that under physiological conditions of vasculogenesis, there is equilibrium between vascular demand and offer.

The present study involving 65 embryos between $7-10$ weeks of age, confirmed the findings of Kurjak et al. [16]. There was a low correlation between 3DPD vascular indices and CRL $(r=0.073, P=0.566$ for $\mathrm{Vl}$; $r=0.173, P=0.168$ for $F I$ and $r=-0.004, P=0.974$ for VFI). These findings support the theory proposed by Kurjak et al. [16] that there would exist a homeostasis between the vascular offer and the embryonic demand at 7-10 weeks of pregnancy.

The study of embryonic vascularization using 3DPD is justifiable because placental development and embryonic organogenesis, critical events of pregnancy, are highly dependent on angiogenesis $[13,15]$ and take place during the first trimester of gestation. Abnormal placental or embryonic vascularization has been associated with early embryonic loss $[3,20]$. Since placental angiogenesis is directly related to embryonic blood flow and there is only one previous publication on this subject [16], we aimed to evaluate the potential application of 3DPD in the estimation of embryonic vascularization. The low correlation between the 3DPD vascular indices and CRL observed in the present study contradicts physiological phenomena that take place during embryonic development and cannot be explained on physiological 
grounds. It has recently been reported that fetuses with trisomy 13 and 18 have reduced placental vascular indices between 11 and $13+6$ weeks, compared to normal fetuses [27]. Further studies need to investigate whether young aneuploid fetuses have reduced vascular indices compared to normal fetuses.

In conclusion, we have shown that 3DPD is a simple and practical method that can be performed between the $7^{\text {th }}$ and $10^{\text {th }}$ week of pregnancy to evaluate quantitavely the vascular development of the embryo. More studies are needed to confirm the applicability of 3DPD in pregnancies at risk for early loss.

\section{References}

[1] American Institute of Ultrasound in Medicine/National Electrical Manufactures Association. Standards for realtime display of thermal and mechanical acoustic output indices on diagnostic equipment. 2nd ed. Rockville: AIUM; 1998.

[2] Aviram R, Shpan KD, Markovitch O, Fishman A, Tepper R. Three-dimensional first trimester fetal volumetry: comparison with crown-rump length. Early Hum Dev. 2004;80: $1-5$.

[3] Bassil S, Magritte JP, Roth J, Nisolle M, Donnez J, Gordts $\mathrm{S}$. Uterine vascularity during stimulation and its correlation with implantation in in-vitro fertilization. Hum Reprod. 1995;10:1497-501.

[4] Benson CB, Doubliet PM. Embryonic heart rate in early first trimester: indicators of poor pregnancy outcome. Radiology. 1994;192:343-4.

[5] Blaas HG, Eik-Nes SH, Berg A, Torp H. In-vivo three dimensional reconstructions of embryos and early fetuses. Lancet. 1998;352:1182-6.

[6] Chang $\mathrm{CH}$, Yu CH, Ko HC, Chang FM, Chen HY. Assessment of normal liver blood flow using quantitative threedimensional power Doppler ultrasound. Ultrasound Med Biol. 2003;29:943-9.

[7] Chang $\mathrm{CH}$, Yu CH, Ko HC, Chen CL, Chang FM. Threedimensional power Doppler ultrasound for the assessment of the fetal brain blood flow in normal gestation. Ultrasound Med Biol. 2003;29:1273-9.

[8] Cho FN, Chen SN, Tai MH, Yang TL. The quality and size of yolk sac in early pregnancy loss. Aust N Z J Obstet Gynaecol. 2006;46:413-8.

[9] Duck FA. Is it safe to use diagnostic ultrasound during the first trimester? Ultrasound Obstet Gynecol. 1999;13: 385-8.

[10] Falcon O, Peralta CF, Cavoretto P, Faiola S, Nicolaides KH Fetal trunk and head volume measured by three-dimensional ultrasound at $11+0$ to $13+6$ weeks of gestation in chromosomally normal pregnancies. Ultrasound Obstet Gynecol. 2005;26:263-6.

[11] Figueras F, Torrents M, Muñoz A, Comas C, Antolin E, Echevarria M, et al. Three-dimensional yolk and gestational sac volume. A prospective study of prognostic value. $J$ Reprod Med. 2003;48:252-6.

[12] Gadelha PS, Da Costa AG, Filho FM, El Beitune P. Amni- otic fluid volumetry by three-dimensional ultrasonography during the first trimester of pregnancy. Ultrasound Med Biol. 2006;32:1135-9.

[13] Guillomot M, Flechon JE, Wintenberg-Torres S. Conceptus attachment in the ewen: an ultra-structural study. Placenta. $1981 ; 2: 169-82$.

[14] Jurkovic D, Gruboeck K, Campbell S. Ultrasound features in normal early pregnancy development. Curr Opin Obstet Gynecol. 1995;7:493-504.

[15] King GJ, Atkison BA, Robertson HA. Implantation and early placentation in domestic ungulates. J Reprod Fertil. 1982;31:17-30.

[16] Kurjak A, Hafner T, Kupesic S, Kostovic L. Three-dimensional power Doppler in study of embryonic vasculogenesis. J Perinat Med. 2002;30:18-25.

[17] Kurjak A, Kupesic S, Banovic I, Hafner T, Kos M. The study of morphology and circulation of early embryo by threedimensional ultrasound and power Doppler. J Perinat Med. 1999;27:145-57.

[18] Lee W, Deter RL, McNie B, Powell M, Balasubramaniam $\mathrm{M}$, Gonçalves LF, et al. Quantitative and morphological assessment of early gestational sacs using three-dimensional ultrasonography. Ultrasound Obstet Gynecol. 2006; 28:255-60.

[19] Martins WP, Ferriani RA, Barra DA, Dos Reis RM, Bortolieiro MA, Nastri CO, et al. Reliability and validity of tissue volume measurement by three-dimensional ultrasound: an experimental model. Ultrasound Obstet Gynecol. 2007;29: 210-14.

[20] Meegdes BH, Ingenhoes R, Peeters LL, Exalto N. Early pregnancy wastage: relationship between chorionic vascularization and embryonic development. Fertil Steril. 1988;49:216-20.

[21] Mercé LT, Barco MJ, Bau S. Reproducibility of the study of placental vascularization by three-dimensional power Doppler. J Perinat Med. 2004;32:228-33.

[22] Mercé LT, Barco MJ, Bau S, Kupesic S, Kurjak A. Assessment of placental vascularization by three-dimensional power Doppler "vascular biopsy" in normal pregnancies. Croat Med J. 2005;46:765-71.

[23] Nyberg NA, Mack LA, Laing FG. Distinguish normal from abnormal gestational sac growth in early pregnancy. $J$ Ultrasound Med. 1987;6:23-7.

[24] Peralta CF, Cavoretto P, Csapo B, Falcon O, Nicolaides $\mathrm{KH}$. Lung and heart volumes by three-dimensional ultrasound in normal fetuses at 12-32 weeks' gestation. Ultrasound Obstet Gynecol. 2006;27:128-33.

[25] Raine-Fenning NJ, Clewes JS, Kendall NR, Bunkheila AK, Campbell BK, Johnson IR. The interobserver reliability and validity of volume calculation from three-dimensional ultrasound datasets in the in vitro setting. Ultrasound Obstet Gynecol. 2003;21:283-91.

[26] Riccabona M, Nelson TR, Pretorius DH. Three-dimensional ultrasound: accuracy of distance and volume measurements. Ultrasound Obstet Gynecol. 1996;7:429-34.

[27] Rizzo G, Capponi A, Cavicchioni O, Vendola M, Arduini D. Placental vascularization measured by three-dimensional power Doppler ultrasound at 11 to $13+6$ weeks' gestation in normal and aneuploid fetuses. Ultrasound Obstet Gynecol. 2007;30:259-62.

[28] Rôlo LC, Nardozza LM, Araujo Júnior E, Nowak PM, Moron AF. Yolk sac volume assessed by three-dimensional 
ultrasonography using the VOCAL method. Acta Obstet Gynecol Scand. 2008;87:499-502.

[29] Rubin JM, Bude RO, Carson PL, Bree RAL, Adler RS. Power Doppler ultrasound: a potentially useful alternative to mean frequency-based color Doppler ultrasound. Radiology. 1994;190:853-6.

[30] Yu CH, Chang CH, Ko HC, Chen WC, Chang FM. Assessment of placental fractional moving blood volume using quantitative three-dimensional power Doppler ultrasound. Ultrasound Med Biol. 2003;29:19-23.

The authors stated that there are no conflicts of interest regarding the publication of this article.

Received July 16, 2008. Revised September 19, 2008. Accepted November 7, 2008. Previously published online March 17, 2009. 